\title{
Quality Assurance in Transition towards a Global Concern
}

\author{
Bernhard Andrea \\ University of Graz, Austria
}

\begin{abstract}
Transparency and comparability of higher education especially in terms of their academic programmes are important issues for today's working environment. Employers are looking for the best staff and students want to have a recognised degree for a national and a global labour market. Strict quality criteria have to assure the effectiveness and comparability of academic programmes for the individual student, the scientific community as well as for the market and industry. This paper provides an overview of my doctoral thesis which outlines examples of selected OECD countries (Austria, Germany, Finland, the United Kingdom, the United States and Canada) with their different ways to implement a quality assurance system. Descriptive country reports of all these national case studies together with expert interviews will show the key objectives to transform and improve their quality assurance systems. The focus is laid on the development of such a system as well as on the different challenges these countries are currently facing.
\end{abstract}

\section{Introduction}

Higher education research is a quite new field of interest and can be seen as a multidisciplinary subject. Researchers from different fields of study are interested in learning about the complexity of higher education. They are looking at higher education from different angles with an educational, management and/or social science approach. This study is based on educational, historical, social as well as economic aspects of higher education in the context of quality assurance.

The doctoral thesis shall both create a new understanding of existing issues and identify new and emerging issues worthy of investigation and explanation in terms of quality assurance in higher education. Hence, this research study aims to investigate the effects of higher education reforms concerning quality assurance issues within national higher education systems. Therefore, this approach explores different ways to deal with these changes and transformations in higher education considering the implications on teaching, research and administration at the system level (nationally and internationally).

\section{Research objectives}

In times of mass higher education and a high complexity of higher education systems gains a great importance. Higher education institutions are confronted with tremendous tensions and transformation processes - they have to react quickly to educational needs of a fast-changing society and have to assert one's position with other higher education providers. Many of these rapid changes have had an impact on the quality of teaching and learning, research as well as the management of higher education in a certain way. Thus, the following main research question underlies this doctoral thesis: What are the further developments of the respective higher education system and how will quality assurance emerge successfully in an international higher education area?

A theoretical framework concentrates on the growth and diversification of higher education systems (concepts of massification and diversification), the increased emphasis of the market (privatisation of higher education) as well as the ongoing globalisation process $[7,9,10]$. These transformations show the diverse dynamics and highlight the need of quality assurance in higher education to enhance, improve and even maintain a quality-focused orientation [2]. Thus, a (nationally and internationally recognised) quality assurance system should be able to guarantee transparency and control of academic programmes and degrees. Nearly all over the world national and internationallyoperating quality assurance agencies have been developed but with different approaches (internal or external procedures, accreditation vs. evaluation, quality audits etc.) [5]. Of course, these ongoing transformation processes shall give an insight to international perspectives and developments concerning higher education in general and quality assurance schemes in particular and are not aiming for a comprehensive framework on all ongoing developments in today's knowledge-based society.

A variety of country reports and comparative research projects on higher education issues have been carried out by international organisations, individual researchers or research teams with their different scientific background $[3,8,13]$. But what is missing are future scenarios of the ongoing transformation processes, a link between countries and their different approaches in quality assurance as well as possible solutions for higher education 
systems to establish a functioning system while still considering their cultural, social and economic diversity.

Thus, this thesis investigates quality assurance policies of six OECD countries: Austria, Germany, Finland, the United Kingdom, the United States of America and Canada. Descriptive country reports serve as basis for conducting expert interviews on the ongoing trends and changes in the respective countries. Next to national experts perspectives from international organisations and known researchers are gathered to gain another insight in this complex field of research and emphasis on the other subquestions as well as the main underlying research question of this thesis.

\section{Methodology}

The emphasis is laid on a multiple holistic case study design in order to gain a comprehensive understanding of multiple national higher education systems in terms of their quality assurance procedures. Hence, the empirical part of this thesis focuses on six country reports which provide an overview of general features on their higher education system (facts and figures, governance and funding, reforms) on the one hand and picture a comprehensive description of different quality assurance mechanisms (development of quality assurance and their agency/agencies, ongoing discussions) on the other hand. Furthermore, an interview and feedback process on the country reports from different executive directors of quality assurance agencies, representatives of ministries or members of higher education institutions (academic and administrative staff, students) is carried to gain a deeper insight on the prevailing situation within these countries out (up to six experts per country). Qualitative interviews have been conducted via email or via telephone with both gathering feedback on the country reports concerning their correctness and asking further questions, as e.g., their opinion on the prevailing quality assurance system and possible future developments.

The expert interviews and the various remarks on the country reports have been taken into consideration in the comparative part of the thesis. After an adjustment of the country reports and a qualitative data analysis of the expert judgements a comparison of the systems has been carried out. The expert interviews provided the basis to show future developments on quality assurance and a possible way to implement a functioning quality assurance system. Furthermore, the expertise of the international perspective shall be taken into account to judge the nature and degree of changes concerning both the national cases and the international transformations processes at the same time.
In summary, the different layers within this empirical research are the following:

(1) case-study approach: description of the specific situation in selected OECD countries (Austria, Germany, Finland, United Kingdom, United States of America, Canada).

(2) expert interviews via email or telephone: experts from national and international organisations/institutions.

(3) qualitative content analysis of the expert interviews.

(4) overall comparison as a combination of the above mentioned approaches: comparison along the country reports and the qualitative content analysis of the expert interviews.

With the help of the combination of these two approaches (descriptive and analytic) overall assumptions on quality assurance in a global context, trends and transformations in quality assurance as well as recommendation will be formulated. At this stage the main findings of the theoretical framework are taken into account and linked to further assumptions of these different concepts. Each dimension is used for the comparison of the six quality assurance systems in their prevailing structure and concerning their future developments.

Thus, the methodological approach of this research is multi-layered: survey research (questionnaires, interviews) next to unobtrusive research [1] (content analysis, analysis of existing statistics, comparative analysis). This combination and integration of quantitative and qualitative steps of analysis is a model of triangulation. The aim is not to determine which approach shows the right outcome but to support each other. The point of intersection of all individual results will give the final outcome. Hence, the objective of triangulation is to enlarge the knowledge and findings gradually and step-by-step through mutual comparison of different scientific approaches to cope with the complexity of the field of higher education [6].

\section{Theory, Methodology and Reality}

The aim of this study was to figure out challenges and developments within quality assurance in higher education concentrating on six national case studies: Austria, Germany, Finland, the United Kingdom, the United States of America and Canada. These case studies shall exemplify the ongoing trends and changes along descriptive country reports and expert interviews. Perspectives from international organisations and known researchers are gathered to gain insight into the international dimension.

As one of the main conclusions quality assurance schemes have to be developed as necessary instruments to adjust higher education institutions to the ongoing transformation processes. Some of the 
main results from the comparative analysis out of the country reports are summed up:

- The overall view on all national higher education systems concerning their quality assurance system provides a very complex picture on multiple different approaches.

- The observed quality assurance systems have taken great efforts to implement their individual, for their purposes relevant quality assurance system that goes along with their economic, social and cultural setting, especially within the last three decades.

- The U.S. has the longest history in quality assurance, especially in terms of accreditation, followed by the UK with a strong focus on research evaluation and accountability procedures. Only within the last decades the other European countries, Finland, Germany and Austria (in that order) started more comprehensive and nation-wide quality assurance procedures. Canada can be seen as an exception with a rather diversified system along their thirteen jurisdictions which mostly concentrate on accreditation.

- The ongoing development in the European countries (Germany, Finland, the UK and partly also in Austria) shows a shift towards audits and reviews of internal quality assurance procedures.

Currently all countries are facing similar challenges or have been confronted with fundamental reforms and dealing differently with internationalisation processes at the same time. Out of the expert views the move towards quality assurance in an international higher education area is visible. Nonetheless, the pressures and challenges on national higher education systems are significantly growing. National quality assurance systems have been developed, have been and still are in the process of transformation and change and do not only face national complexities within the differences at system, institutional and programme level but also have to deal with an international dimension.

\section{Conclusion}

Although there are lots of different national opinions and ways to implement a quality assurance system, there is a need and a will to cooperate between this diversity while still keeping the individuality of the own country [3]. As the different systems are most of the time newly developed they should be able to adapt to changes and try to react quickly to the needs of our knowledge-based society.

The research findings and outcomes provide some useful guidelines and recommendations for upcoming challenges of the observed higher education systems and beyond their national borders.

Recommendation 1: Less diversification within a higher education sector at system, institutional and programme level would enhance the establishment of a functioning quality assurance system. Peculiarities and innovative solutions of a national higher education system have to be sustained and shall be supported though too much complexity within a system is a hindering factor. The observed country cases with their individual quality assurances system shall find a balance between over-diversification and over-homogenisation [12]. Throughout all countries a comparability within and also with other national systems is needed and common procedures, standards, profiles or results are necessary especially within rather decentralised systems.

Recommendation 2: Higher education should be made more comparable and transparent through detailed and reliable information on the quality of individual study programmes, faculties and higher education institutions [4]. Innovative transparency tools have to be developed, e.g. through rankings. Higher education institutions are much more involved in rankings, benchmarking and other quality assurance procedures if their funding streams are highly diversified and derived from different sources (e.g. tuition fees, education contracts, third party money).

Recommendation 3: Higher education is much more oriented towards the different perspectives of stakeholders. Hence, a continuing engagement of all stakeholders in quality assurance matters (especially students), an improved awareness of all stakeholders on the expectations of quality assurance mechanisms, a greater orientation towards the impact of quality assurance (e.g. learning outcomes), common projects with different stakeholders and an exchange of know-how would be helpful.

Recommendation 4: A continuing trend towards quality assurance in an international higher education area is predominant. This international dimension within quality assurance shall be supported by an exchange of staff and know-how as well as different innovative solutions, e.g. through international quality assurance projects. Higher education across borders is a promising path to enhance especially the quality of higher education and therefore common standards at international level to increase international comparability of quality assurance frameworks are needed (good examples: OECD/UNESCO Guidelines for quality provision in cross-border higher education, European Standards and Guidelines, European Quality Assurance Register, international rankings, benchmarking projects). In that sense diverse, stratified, hierarchical (possibly 'joined-up') system of higher education seems the most realistic (and likely) response to the steady globalisation of research and teaching in higher education, and the most likely product of the changing relationship between the state and the market in its delivery [11]

Of course, there is not one single approved solution which way is more suitable for all countries. 
Nonetheless, the different national approaches show that all countries are trying to follow both their national peculiarities and international developments at the same time. All countries aim for increased international co-operation to attract more students from abroad and in this way generate more income emphasising on their respective national approach. In that sense, quality assurance systems shall be better prepared to respond to an environment that is becoming increasingly more market-oriented and competitive to generate more and diversified sources of income through, for instance, international students (tuition fees) or research contracts with other international partners. Especially, in times of financial crisis the funding of higher education is incrementally affected. Thus, higher education has to assure their high quality to gain additional public as well as private income and to compete with other higher education providers in this increasingly diversified higher education area. Those higher education institutions, which react more effectively on these pressures concerning a decline of income and a competition between institutions as well as for the best students, are expected to build up a functioning quality assurance system that is able to face the challenges of the upcoming decades.

These recommendations shall support policy makers, higher education staff members, quality assurance agencies, international organisations as well as other stakeholders which are involved in the field of quality assurance to get familiar with different quality assurance systems and approaches and to judge further developments in this field. To show how higher education is influenced by quality assurance mechanisms this thesis shall provide more clarity but also serve a plea for those higher education institution that are not on the road to assure their quality. Quality assurance in higher education is not fully developed but still under construction!

\section{References}

[1] Babbie, E., 1983, 'The practice of social research. Belmont: Wadsworth'. $3^{\text {rd }}$ edition.

[2] Bernhard, A., 2009, 'A knowledge-based society needs quality in higher education', Problems of Education 12 (12), pp. 15-21.

[3] Bollaert, L. et al. (Eds.), 'Trends in Quality Assurance, A Selection of Papers from the $3^{\text {rd }}$ European Forum for Quality Assurance, 20 - 22 November 2008', EUA: Corvinus University Budapest, EUA Case Studies 2009.

[4] ENQA, 2009, 'Position Paper on Quality Assurance in the EHEA in view of the Leuven and Louvain-la-Neuve meeting of ministers responsible for higher education of 28-29 April 2009';

http://www.enqa.eu/files/ENQA_position_paper\%20(3).pd f (1 December 2010)
[5] Harvey, L., and Green, D., 1993, 'Defining quality'. Assessment and Evaluation in Higher Education 18(1), pp. 9-34.

[6] Lamnek, S., 2005, 'Qualitative Sozialforschung. Ein Lehrbuch’, Weinheim/Basel: Beltz Verlag, $3^{\text {rd }}$ edition.

[7] OECD, 'Higher Education to 2030, Vol. 2 Globalisation', OECD Publishing: Paris.

[8] Roca, A.G. et al. (Eds.), 2007, 'Higher Education in the World. Accreditation for Quality Assurance: What is at Stake?', Palgrave: Hampshire/New York, Guni Series on the Social Commitment of Universities, vol.2.

[9] Santiago, P. et al., 2008, 'Tertiary education for knowledge society. OECD Thematic Review of Tertiary Education: Synthesis Report, Vol.1-3', OECD Publishing: Paris.

[10] Trow, M., 1973, 'Problems in the transition from elite to mass higher education', Carnegie Commission on Higher Education: Berkley.

[11] Tapper, T. and Palfreyman, D., 2004, 'Convergence and Divergence in the Global Model of Mass Higher Education: Predictions for 2010', CHEPS: Oxford, OxCHEPS Occasional Paper, vol.14.

[12] Teichler, U., 2007, 'Higher education systems. Conceptual frameworks, comparative perspectives, empirical findings', Sense Publishers: Rotterdam.

[13] Westerheijden, D.F. et al. (Eds.), 2007, 'Quality Assurance in Higher Education. Trends in Regulation, Translation and Transformation', Springer: Dordrecht, Higher Education Dynamics, vol.20. 